\title{
A study on the machining parameters optimization of micro-end milling process
}

\author{
PR.Periyanan $^{1 *}$, U.Natarajan ${ }^{2}$, S.H.Yang ${ }^{3}$ \\ ${ }^{1 *}$ Department of Mechanical Engineering, Sudharsan Engineering College, INDIA \\ ${ }^{2}$ Department of Mechanical Engineering, A.C.College of Engineering \& Technology, INDIA \\ ${ }^{3}$ Department of Mechanical Engineering, Kyungpook National University, SOUTH KOREA \\ ${ }^{*}$ Corresponding Author: e-mail: prp_me@yahoo.co.in,
}

\begin{abstract}
Micro-machining is the basic technology of micro-engineering for the production of micro-sized parts and components. Microend milling is the most important micromachining process, widely used for the manufacturing industries due to its capability of producing tedious geometric surfaces with good accuracy and surface finish. In micro end milling material removal rate is one of the important aspects, which require attention both from industry personnel as well as in Research and development. In modern industry one of the trends is to manufacture low cost product in short time. MRR which indicates processing time of the work piece and it is an important factor that greatly influences production rate and cost. MRR greatly vary with the change of cutting process parameters. This paper focuses the taguchi technique for the optimization in micro-end milling operation to achieve maximum metal removal rate (MRR) considering the spindle speed, feed rate and depth of cut as the cutting parameters. An orthogonal array, signal-to-noise (S/N) ratio and Pareto analysis of variance (ANOVA) are employed to analyze the effect of these milling parameters. The analysis of the result shows that the optimal combination for higher metal removal rate (MRR) is medium cutting speed, high feed rate and high depth of cut. Using Taguchi method for design of experiment (DOE), other significant effects such as the interaction among milling parameters are also investigated. The study shows that the Taguchi method is suitable to solve the stated problem. Based on the verification experiment it is concluded that the percentage of error of response was less.
\end{abstract}

Keywords: Taguchi method of DOE, optimization, micro-end milling, MRR, Pareto ANOVA

DOI: http://dx.doi.org/10.4314/ijest.v3i6.19

\section{Introduction}

Highly accurate miniaturized components are increasingly in demand for various industries such as aerospace, biomedical, electronics, environmental, communications and automotive. Micro-machining is the process of manufacturing the microcomponents by using the miniaturized technologies. Miniature systems can provide portability, disposability, lower material and power consumption, lower sample requirements, higher heat transfer and the capability of better process integration and automation. Micro-components fabrication requires reliable and accurate process technologies and tools. Now-a-days micro-end milling process is very useful to produce three dimensional forms of micro-sized products in a wide range of materials. Li et al. (2007) developed the three dimensional cutting force model for micro-scale end milling. The tool based micro-machining is gaining popularity because of its machining efficiency (Asad et al., 2007; Rahman et al., 2005). Rahman et al. (2007) discussed about the recent achievements in the important areas of tool based micro-machining .Yang et al. (2011) investigated the temperature distribution of the micro cutter in the micro end milling process. Many research publications show that micro- EDM is used to fabricate functional micro-structures and components (Bigot et al 2006) because this non-contact process requires little or almost no force between the tool-electrode and work-piece. It is important that every discharge location is uniformly distributed over the working surface for reducing the tool wear and surface roughness of the work-piece (Yu et al., 1998). Also in micro-EDM 
process the work-piece material should be electrically conductive. Lee et al. (2004) conducted a set of experiments to begin the characterization of surface quality for the micro end milling process. Wang et al. (2005) discussed the surface roughness of brass, machined by micro-end milling miniaturized machine tool. The value of surface roughness increased linearly with increase of tool diameter and spindle speed; feed rate played an important role when other parameters are constant. Popov et al. (2010) proposed a new solution to improve reliability and reduce uncertainty in micro machining operations. The proposed methodology was used to improve the precision and the quality of the machined micro components and ultimately to reduce the machining cost in micro manufacturing. In micro-machining processes the various models of cutting force, surface roughness, tool wear etc., are different from conventional machining processes .since the resistance force (viscous force) dominates the inertia (motive) force for the micro-sized components. The Reynolds number is defined as the ratio of inertia force to the viscous force. The Reynolds number is less than unity in the micro-size components,, because of the size effect (Fujimasa, 1996). So, the rubbing and burnishing actions will lead to the elastic-plastic deformation when the chip thickness is very low, thereby increasing the cutting force and power consumption. Presently, micro-end milling is widely used for machining free form curves. Baw and Tansel (2000) discussed about the cutting force model and tool wear model for micro-end milling considering the trajectory of the tool tip while the tool rotated and moved continuously. Son et al. (2005) investigated that the best surface finish was produced when the chip thickness is minimum with continuous chip and further observed that feed is having influence for the surface roughness of the work-piece. Bissacco et al. (2010) discussed about the wear and material removal in micro-EDM milling for selected process parameter combinations typical of rough and finish machining of micro-features in steel. The influences of the accuracy of volume measurements on the electrode wear per discharge and on the material removal per discharge were discussed. Ghani et al. (2004) outlines the Taguchi optimization methodology, which is applied to optimize cutting parameters in end milling when machining hardened steel AISI H13 with TiN coated P10 carbide insert tool under semi-finishing and finishing conditions of high speed cutting. The milling parameters evaluated are cutting speed, feed rate and depth of cut. An orthogonal array, signal-to-noise $(\mathrm{S} / \mathrm{N})$ ratio and Pareto analysis of variance (ANOVA) are employed to analyze the effect of these milling parameters. Malekian et al. (2009) examine the factors affecting tool wear and a tool wear monitoring method using various sensors. Several cutting tests were performed to verify the monitoring scheme for the miniature micro-end mills. Prakash et al. (2001) investigated that the flank wear at the end of the cutting edge is the highest and that the feed rate and cutting speed have more significant influence over microcutting tool than axial depth of cut for the coated micro-end mill. Rahman et al. (2001) concluded that for small depth of cut $(0.15 \mathrm{~mm})$, the tool wear rate was higher than large depth of cut $(0.25)$, in micro-milling of copper.

The principle of micro-machining is similar to those of conventional cutting operations. The surface of the work-piece is mechanically removed using micro-tools. In micro-machining operations, the rotational speed of spindle should be very high to maintain acceptable productivity since the small tool diameter decrease the chip removal rate. Micro-end milling is emerging as an important micro-machining process and it is widely used in most of the manufacturing industries due to its capability of producing complex geometric surfaces with reasonable accuracy and surface finish. In micro end milling material removal rate is one of the important aspects, which require attention both from industry personnel as well as in Research and development. In modern industry one of the trends is to manufacture low cost product in short time. MRR which indicates processing time of the work piece and it is an important factor that greatly influences production rate and cost. MRR greatly vary with the change of cutting process parameters. That is why the proper selection of process parameter is essential for maximum MRR in micro-end milling process. Literature review reveals that the researchers have carried out most of the work on micro-machining processes developments, monitoring and control but very limited work has been reported on optimization of process parameters. In this work, the length of tool, radius and fluits are considered as constant and also tool deflection and tool wear is considered as negligible. This paper focuses the taguchi technique for the optimization in micro-end milling operation to achieve maximum metal removal rate (MRR) considering the spindle speed, feed rate and depth of cut as the cutting parameters. Material removal rate which indicates processing time of the work piece is important factor that greatly influences production rate and cost. It is necessary to study the material removal rate in micro-end milling process. Because of these, MRR is taken as output response. An orthogonal array, signal-to-noise (S/N) ratio and Pareto analysis of variance (ANOVA) are employed to analyze the effect of these milling parameters. Using Taguchi method for design of experiment (DOE), other significant effects such as the interaction among milling parameters are also investigated.

\section{Taguchi technique}

The Taguchi technique involves reducing the variation in a process through robust design of experiments. The overall objective of the method is to produce high quality product at low cost to the manufacturer. Taguchi's parameter design is an important tool for robust design. It offers a single and systematic technique to optimize the design performance, quality and cost. Two major tools used in robust design are (Park 1996, Unal et al 1991, Phadke 1989).

a. Signal to noise ratio(S/N), which measures quality with emphasis on variation and

b. Orthogonal arrays, which accommodate many design factors simultaneously

When a critical quality characteristics deviates from the target value it causes a loss. Continuously pursuing variable reduction from the target value in critical quality characteristics is the key to achieve high quality and reduce cost. In Taguchi method, signal 
to-noise $(\mathrm{S} / \mathrm{N})$ is used to represent a response or quality characteristic and the largest $\mathrm{S} / \mathrm{N}$ ratio is required. There are usually three types of quality characteristics, i.e. target-the-best, larger-the-better and smaller-the better.
1. Target-the-best:
$\mathrm{S} / \mathrm{N}=10 \log \frac{\bar{y}}{s^{2} y}$
2. Larger-the-better:

$$
\mathrm{S} / \mathrm{N}=-10 \log \frac{1}{n}\left(\sum \frac{1}{y^{2}}\right)
$$
3. Smaller-the-better:

$$
\mathrm{S} / \mathrm{N}=-10 \log \frac{1}{n}\left(\sum y^{2}\right)
$$

where, $\mathrm{y}$ is the measured data, $\bar{y}$ is the average of measured data, $s_{y}^{2}$ is the variance of $\mathrm{y}$ and $\mathrm{n}$ is the number of samples. For each type of the characteristics, with the above $\mathrm{S} / \mathrm{N}$ ratio transformation, the higher the $\mathrm{S} / \mathrm{N}$ ratio the better is the result.

\section{Experimental procedure}

Normally $\mathrm{L}_{9}$ orthogonal arrays can be used with 9 trial instead of 27 as presented in the paper. But for more accuracy the orthogonal array is selected based on the DOF. Here, For 3 parameters each at three levels (degree of freedom $=2+2+2$ ) and three interaction (degree of freedom $=4+4+4$ ), so the total $\mathrm{DOF}=18$, The number of DOF for orthogonal array should be greater than or equal to the number of DOF required. Hence here $\mathrm{L}_{27}$ orthogonal array is selected. In this experiment with three factors at three levels each, the fractional factorial design used is a standard $\mathrm{L}_{27}\left(3^{13}\right)$ orthogonal array. The standard $\mathrm{L}_{27}\left(3^{13}\right)$ orthogonal array table (as shown in Table 2) with factors A , and C arranged in columns 2, 5, and 6 respectively. The inrteractions among factors are indicated as in column 1, 7,8,9,11 and 12. (Singh and Kumar, 2004).This orthogonal array is chosen due to its capability to check the interactions among the factors. Each row of the matrix represents one trial. However, the sequence in which these trials are carried out is randomized. The three levels of each factor are represented by a ' 0 ' or a ' 1 ' or a ' 2 ' in the matrix. The factors and levels are assigned as in Table 1.

The experimental works were performed as per the trial in a three axis custom-built micro-end milling machine as shown in Fig.1. Two stages of sizes 120x120mm (Surega Seiki-KS 103-70) and 120x160mm (KS 103-100) were built for X-Y and $\mathrm{Z}$ (spindle axis) axes respectively. The maximum travel of $\mathrm{X}-\mathrm{Y}$ stage is $70 \mathrm{~mm}$ whereas the maximum travel of $\mathrm{Z}$ stage is $100 \mathrm{~mm}$. The spindle is driven by the compressed air and the spindle speed varies from 60,000 to 80,000 rpm. Aluminium block of $60 \times 40 \times 16 \mathrm{~mm}$ is used as the work-piece material and carbide end-mill cutter of diameter $1 \mathrm{~mm}$ as the cutting tool. A total number of 27 experiments was conducted. The spindle speed $(A)$, feed $\operatorname{rate}(B)$ and $\operatorname{depth}$ of $\operatorname{cut}(C)$ are considered as input machining parameters and MRR is taken as output response. The responses of MRR were measured for the various sets of experimental data as shown in Table 3. MRR is the amount of work-piece material removed per unit time, which can be measured by the image captured with the use of optical measurement method.

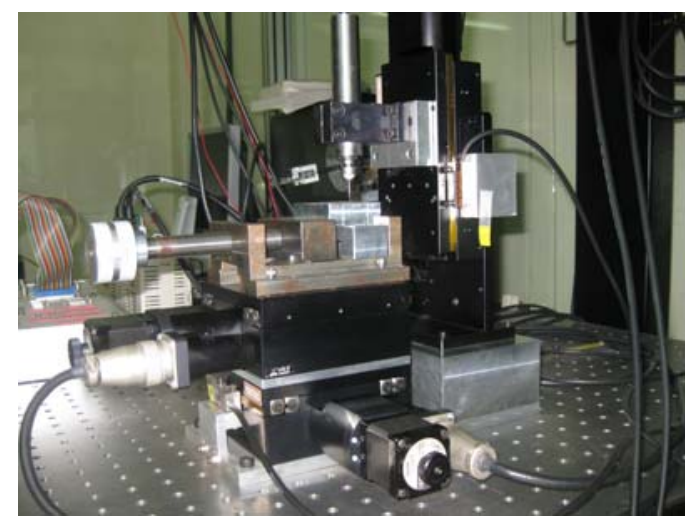

Fig.1 Experimental set-up of micro-end milling machine 
Table 1 Selected machining parameter levels

\begin{tabular}{|l|c|c|c|}
\hline \multirow{2}{*}{\multicolumn{1}{|c|}{ Factors }} & \multicolumn{3}{|c|}{ Levels } \\
\cline { 2 - 4 } & Low (-) & Medium (0) & High (+) \\
\hline Spindle speed $(A)$ in rpm & 60,000 & 70,000 & 80,000 \\
Feed rate $(B)$ in $\mu \mathrm{m} / \mathrm{sec}$ & 0.2 & 0.5 & 0.8 \\
Depth of cut $(C)$ in $\mu \mathrm{m}$ & 10 & 25 & 40 \\
\hline
\end{tabular}

\section{Results and discussions}

Usually performance of various types of cutting operator is judged by different measures. In case of rough cutting operation, the metal removal rate is the primary importance whereas in finishing operation the surface roughness is primary importance. Material removal rate which indicates processing time of the work piece is important factor that greatly influences production rate and cost. Because of these it is necessary to study the material removal rate in micro-end milling process. In order to assess the effect of each machining parameter on the micro end milling process, the Taguchi technique is used. This technique is type of statistical technique called Design of Experiments (DOE) that makes it possible to analyses the effect of more than one factor at the same time while reducing the number of experiments. Thus using the Taguchi approach, the design of experiments and analysis of results can be done with less effort and expenses. Hence this technique considerably reduces the number of experiments. One important step in the Taguchi technique is the identification of the control factors and of their values considered for investigation. These factor levels should be placed very carefully, since the Taguchi technique defines the significant and optimal parameters only within the selected range. The levels of parameters that affect the performance of the micro-end milling process are identified based on, survey of literature and preliminary experimentation performed by authors by considering more number of variables. Through the above observation the levels of parameters, which vigorously affect MRR was selected.

Table: 2.Orthogonal array for $\mathrm{L}_{27}\left(3^{13}\right)$ Taguchi design.

\begin{tabular}{|c|c|c|c|c|c|c|c|c|c|c|c|c|c|}
\hline $\begin{array}{l}\text { Column } \\
\text { Trial }\end{array}$ & $\begin{array}{l}\text { BXC } \\
1\end{array}$ & $\begin{array}{l}\mathbf{A} \\
2\end{array}$ & 3 & 4 & $\begin{array}{l}\text { B } \\
5\end{array}$ & $\begin{array}{l}\text { C } \\
6\end{array}$ & $\begin{array}{l}\text { BXC } \\
7\end{array}$ & $\begin{array}{l}\text { AXB } \\
8\end{array}$ & $\begin{array}{l}\text { AXC } \\
9\end{array}$ & $\begin{array}{l}- \\
10\end{array}$ & $\begin{array}{l}\text { AXB } \\
11\end{array}$ & $\begin{array}{l}\text { AXC } \\
12\end{array}$ & $\begin{array}{l}- \\
13\end{array}$ \\
\hline 1 & 0 & 0 & 0 & 0 & 0 & 0 & 0 & 0 & 0 & 0 & 0 & 0 & 0 \\
\hline 2 & 0 & 0 & 0 & 0 & 1 & 1 & 1 & 1 & 1 & 1 & 1 & 1 & 1 \\
\hline 3 & 0 & 0 & 0 & 0 & 2 & 2 & 2 & 2 & 2 & 2 & 2 & 2 & 2 \\
\hline 4 & 0 & 1 & 1 & 1 & 0 & 0 & 0 & 1 & 1 & 1 & 2 & 2 & 2 \\
\hline 5 & 0 & 1 & 1 & 1 & 1 & 1 & 1 & 2 & 2 & 2 & 0 & 0 & 0 \\
\hline 6 & 0 & 1 & 1 & 1 & 2 & 2 & 2 & 0 & 0 & 0 & 1 & 1 & 1 \\
\hline 7 & 0 & 2 & 2 & 2 & 0 & 0 & 0 & 2 & 2 & 2 & 1 & 1 & 1 \\
\hline 8 & 0 & 2 & 2 & 2 & 1 & 1 & 1 & 0 & 0 & 0 & 2 & 2 & 2 \\
\hline 9 & 0 & 2 & 2 & 2 & 2 & 2 & 2 & 1 & 1 & 1 & 0 & 0 & 0 \\
\hline 10 & 1 & 0 & 1 & 2 & 0 & 1 & 2 & 0 & 1 & 2 & 0 & 1 & 2 \\
\hline 11 & 1 & 0 & 1 & 2 & 1 & 2 & 0 & 1 & 2 & 1 & 1 & 2 & 0 \\
\hline 12 & 1 & 0 & 1 & 2 & 2 & 0 & 1 & 2 & 0 & 0 & 2 & 0 & 1 \\
\hline 13 & 1 & 1 & 2 & 0 & 0 & 1 & 2 & 1 & 2 & 0 & 2 & 0 & 1 \\
\hline 14 & 1 & 1 & 2 & 0 & 1 & 2 & 0 & 2 & 0 & 1 & 0 & 1 & 2 \\
\hline 15 & 1 & 1 & 2 & 0 & 2 & 0 & 1 & 0 & 1 & 2 & 1 & 2 & 0 \\
\hline 16 & 1 & 2 & 0 & 1 & 0 & 1 & 2 & 2 & 0 & 1 & 1 & 2 & 0 \\
\hline 17 & 1 & 2 & 0 & 1 & 1 & 2 & 0 & 0 & 1 & 2 & 2 & 0 & 1 \\
\hline 18 & 1 & 2 & 0 & 1 & 2 & 0 & 1 & 1 & 2 & 0 & 0 & 1 & 2 \\
\hline 19 & 2 & 0 & 2 & 0 & 0 & 2 & 1 & 0 & 2 & 1 & 0 & 2 & 1 \\
\hline 20 & 2 & 0 & 2 & 0 & 1 & 0 & 2 & 1 & 0 & 2 & 1 & 0 & 2 \\
\hline 21 & 2 & 0 & 2 & 0 & 2 & 1 & 0 & 2 & 1 & 0 & 2 & 1 & 0 \\
\hline 22 & 2 & 1 & 0 & 1 & 0 & 2 & 1 & 1 & 0 & 2 & 2 & 1 & 0 \\
\hline 23 & 2 & 1 & 0 & 1 & 1 & 0 & 2 & 2 & 1 & 0 & 0 & 2 & 1 \\
\hline 24 & 2 & 1 & 0 & 1 & 2 & 1 & 0 & 1 & 2 & 1 & 1 & 0 & 2 \\
\hline 25 & 2 & 2 & 1 & 2 & 0 & 2 & 1 & 2 & 1 & 0 & 1 & 0 & 2 \\
\hline 26 & 2 & 2 & 1 & 2 & 1 & 0 & 2 & 0 & 2 & 1 & 2 & 1 & 0 \\
\hline 27 & 2 & 2 & 1 & 2 & 2 & 1 & 0 & 1 & 0 & 2 & 0 & 2 & 1 \\
\hline
\end{tabular}


The main objective of this experimental work is to optimize the micro end milling parameters to achieve the higher value of MRR, the higher the better characteristics is used. The table 2 shows the actual value for MRR along with their computed S/N ratio. The table 4 shows the response table for average $\mathrm{S} / \mathrm{N}$ ratio for MRR factors and significant interaction. The mean $\mathrm{S} / \mathrm{N}$ ratio for the parameter and interactions are calculated from the measured response table 3 with respect to the levels. The graphical representations of these data are as shown in figure 3. Taguchi recommends analyzing the mean and $\mathrm{S} / \mathrm{N}$ ratio using conceptual approach that involves graphing the effects and visually identifying the factors that appear to be significant, without using ANOVA, because of these the analysis is simple. From the graphical representation of the factors and their interaction results shows that the medium level of spindle speed and interaction between feed rate and depth of cut are significant. Also from the graphs, we conclude that the spindle speed, feed rate and depth of cut is more significant. The higher value of MRR was obtained when the spindle speed is medium in range. The two ways table BXC is used [S.H.Park 1996] to select their levels as calculated and the values are as shown in Table 5. Based on the results of two way table BXC, it is concluded that the optimum combination of factor $\mathrm{B}$ and factor $\mathrm{C}$ gives good result. The optimum combination of that factor is $\mathrm{B}_{2} \mathrm{C}_{2}$. Therefore the optimal combination to get the higher value of MRR is $\mathrm{A}_{1} \mathrm{~B}_{2} \mathrm{C}_{2}$ within the tested range of experiment.

Pareto ANOVA is one of the techniques to analyze the data for the optimization. It is a simplified ANOVA method which uses Pareto principles. It is a quick and easy method to analyze the results of parameter design. The Pareto ANOVA technique of analysis has been performed, which requires least knowledge about ANOVA method and suitable for engineers. The table 6 shows the Pareto ANOVA analysis for MRR. From the Pareto ANOVA method, the results of shows that the spindle speed (factor A), feed rate (factor B)and depth of cut (factor C) have strong influence on the MRR. Based on the result it is concluded that, higher the MRR was obtained at medium value of spindle speed, higher value of feed rate and higher value of depth of cut. That is the optimal combination to get the higher value of MRR is $\mathrm{A}_{1} \mathrm{~B}_{2} \mathrm{C}_{2}$ within the tested range of experiment.

Table 3 Experimental design, measured responses and their corresponding $\mathrm{S} / \mathrm{N}$ ratio

\begin{tabular}{|c|c|c|c|c|c|c|}
\hline \multirow{2}{*}{ Exp.No } & \multicolumn{3}{|c|}{ Factor } & \multirow{2}{*}{ Designation } & \multicolumn{2}{c|}{ Measured responses and their corresponding S/N ratio } \\
\cline { 2 - 3 } & $\mathbf{A}$ & $\mathbf{B}$ & $\mathbf{C}$ & & MRR ( $\left.\mathbf{m m}^{3} / \mathbf{m i n}\right)$ & S/N ratio for MRR(db) \\
\hline 1 & 0 & 0 & 0 & $\mathrm{~A}_{0} \mathrm{~B}_{0} \mathrm{C}_{0}$ & 0.06 & -2.444 \\
\hline 2 & 0 & 1 & 1 & $\mathrm{~A}_{0} \mathrm{~B}_{1} \mathrm{C}_{1}$ & 0.19 & -1.442 \\
\hline 3 & 0 & 2 & 2 & $\mathrm{~A}_{0} \mathrm{~B}_{2} \mathrm{C}_{2}$ & 0.52 & -0.568 \\
\hline 4 & 1 & 0 & 0 & $\mathrm{~A}_{1} \mathrm{~B}_{0} \mathrm{C}_{0}$ & 0.22 & -1.315 \\
\hline 5 & 1 & 1 & 1 & $\mathrm{~A}_{1} \mathrm{~B}_{1} \mathrm{C}_{1}$ & 0.52 & -0.568 \\
\hline 6 & 1 & 2 & 2 & $\mathrm{~A}_{1} \mathrm{~B}_{2} \mathrm{C}_{2}$ & 1.33 & 0.248 \\
\hline 7 & 2 & 0 & 0 & $\mathrm{~A}_{2} \mathrm{~B}_{0} \mathrm{C}_{0}$ & 0.29 & -1.075 \\
\hline 8 & 2 & 1 & 1 & $\mathrm{~A}_{2} \mathrm{~B}_{1} \mathrm{C}_{1}$ & 0.45 & -0.694 \\
\hline 9 & 2 & 2 & 2 & $\mathrm{~A}_{2} \mathrm{~B}_{2} \mathrm{C}_{2}$ & 0.48 & -0.638 \\
\hline 10 & 0 & 0 & 1 & $\mathrm{~A}_{0} \mathrm{~B}_{0} \mathrm{C}_{1}$ & 0.09 & -2.092 \\
\hline 11 & 0 & 1 & 2 & $\mathrm{~A}_{0} \mathrm{~B}_{1} \mathrm{C}_{2}$ & 0.22 & -1.315 \\
\hline 12 & 0 & 2 & 0 & $\mathrm{~A}_{0} \mathrm{~B}_{2} \mathrm{C}_{0}$ & 0.19 & -1.442 \\
\hline 13 & 1 & 0 & 1 & $\mathrm{~A}_{1} \mathrm{~B}_{0} \mathrm{C}_{1}$ & 0.29 & -1.075 \\
\hline 14 & 1 & 1 & 2 & $\mathrm{~A}_{1} \mathrm{~B}_{1} \mathrm{C}_{2}$ & 1.17 & 0.136 \\
\hline 15 & 1 & 2 & 0 & $\mathrm{~A}_{1} \mathrm{~B}_{2} \mathrm{C}_{0}$ & 0.32 & -0.990 \\
\hline 16 & 2 & 0 & 1 & $\mathrm{~A}_{2} \mathrm{~B}_{0} \mathrm{C}_{1}$ & 0.29 & -1.075 \\
\hline 17 & 2 & 1 & 2 & $\mathrm{~A}_{2} \mathrm{~B}_{1} \mathrm{C}_{2}$ & 0.45 & -0.694 \\
\hline 18 & 2 & 2 & 0 & $\mathrm{~A}_{2} \mathrm{~B}_{2} \mathrm{C}_{0}$ & 0.35 & -0.912 \\
\hline 19 & 0 & 0 & 2 & $\mathrm{~A}_{0} \mathrm{~B}_{0} \mathrm{C}_{2}$ & 0.19 & -1.442 \\
\hline 20 & 0 & 1 & 0 & $\mathrm{~A}_{0} \mathrm{~B}_{1} \mathrm{C}_{0}$ & 0.13 & -1.772 \\
\hline 21 & 0 & 2 & 1 & $\mathrm{~A}_{0} \mathrm{~B}_{2} \mathrm{C}_{1}$ & 0.32 & -0.990 \\
\hline 22 & 1 & 0 & 2 & $\mathrm{~A}_{1} \mathrm{~B}_{0} \mathrm{C}_{2}$ & 0.40 & -0.796 \\
\hline 23 & 1 & 1 & 0 & $\mathrm{~A}_{1} \mathrm{~B}_{1} \mathrm{C}_{0}$ & 0.29 & -1.075 \\
\hline 24 & 1 & 2 & 1 & $\mathrm{~A}_{1} \mathrm{~B}_{2} \mathrm{C}_{1}$ & 1.14 & -0.114 \\
\hline 25 & 2 & 0 & 2 & $\mathrm{~A}_{2} \mathrm{~B}_{0} \mathrm{C}_{2}$ & 0.32 & -1.075 \\
\hline 26 & 2 & 1 & 0 & $\mathrm{~A}_{2} \mathrm{~B}_{1} \mathrm{C}_{0}$ & 0.29 & -0.754 \\
\hline 27 & 2 & 2 & 1 & $\mathrm{~A}_{2} \mathrm{~B}_{2} \mathrm{C}_{1}$ & 0.42 & \\
\hline & & & & & & \\
\hline
\end{tabular}

From the above two techniques of data analysis draw similar conclusions. In this work, the diameter of micro end milling cutter is $1 \mathrm{~mm}$ was used. In most of the micro end milling operations, the diameters of a micro cutting tool vary from $0.1 \mathrm{~mm}$ to $1 \mathrm{~mm}$. The 
stress on the micro cutting tool is higher than the conventional scale tool, which drastically shortens the tool life. The figure 3 shows the magnified image of micro end milling cutter after machining with optimized level of machining parameters. From figure 3 we concluded that the tool wear was occurred at optimized level of cutting parameters. Because, the tool chatter is easy to generate due to the periodical cutting force. But from the figure 3 it is concluded that the wear was very negligible amount. High spindle speed causes the vibration of miniaturized machine tool and the tool geometry is changed with the temperature increasing. The feed per tooth in micro-end milling may be comparable to or even less than the cutting edge radius because of the required range of process parameters for a stable machining scale with the process. If the cutting conditions of micro end milling process is not selected, properly, micro tool will be broken in few seconds. So the experimental design is relatively important factor for micro-end milling process. In this experimental work it is concluded from the pareto diagram, the individual influence of parameter such as spindle speed, feed rate and depth of cut were more than its interaction effect, also use of medium value of spindle speed, higher value of depth of cut and higher value of feed rate are recommended to obtain the maximum MRR in microend milling process. The optimum micro-end milling process parameters for maximum MRR are determines as spindle speed $=$ 70000rpm, feed rate $=0.8 \mu \mathrm{m} / \mathrm{sec}$ and depth of cut $=40 \mu \mathrm{m}$. The optimized machining parameters were used for the confirmation of experiments for validation; the measured value for the MRR is $1.38 \mathrm{~mm}^{3} / \mathrm{min}$. For further scope of work the parameters of cutting tools such as length, radius and fluits, also other constraints such as tool deflection and tool wear can be consider for optimization.

Table: 4. Response table for Average $\mathrm{S} / \mathrm{N}$ ratio for $\mathrm{MRR}$ and significant interaction

\begin{tabular}{|l|l|l|l|l|l|}
\hline Symbol & Cutting parameters & \multicolumn{5}{|c|}{ Mean S/N ratio } \\
\cline { 3 - 6 } & & Level 0 & Level 1 & Level 2 & Max.- Min. \\
\hline A & Spindle speed & -1.501 & -0.591 & -0.879 & 0.288 \\
\hline B & Feed rate & -1.367 & -0.944 & -0.659 & 0.285 \\
\hline C & Depth of cut & -1.344 & -0.953 & -0.673 & 0.280 \\
\hline BXC & Interaction BXC & -0.944 & -1.051 & -0.976 & 0.032 \\
\hline
\end{tabular}

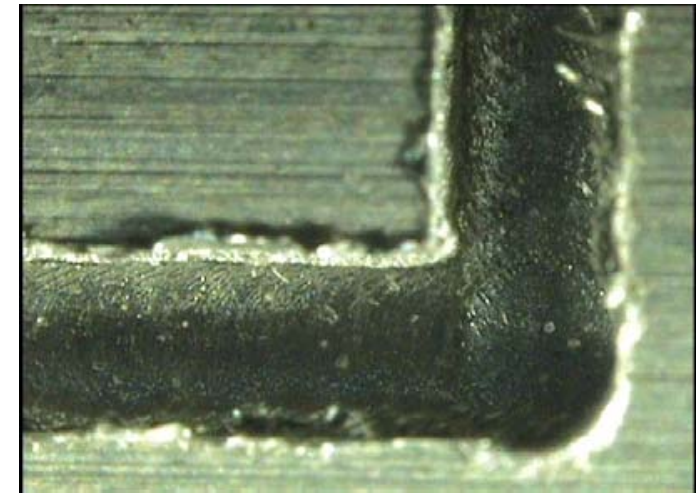

Fig.2 The magnified image (3X)of machined workpiece (multi pass) with optimized cutting parameters

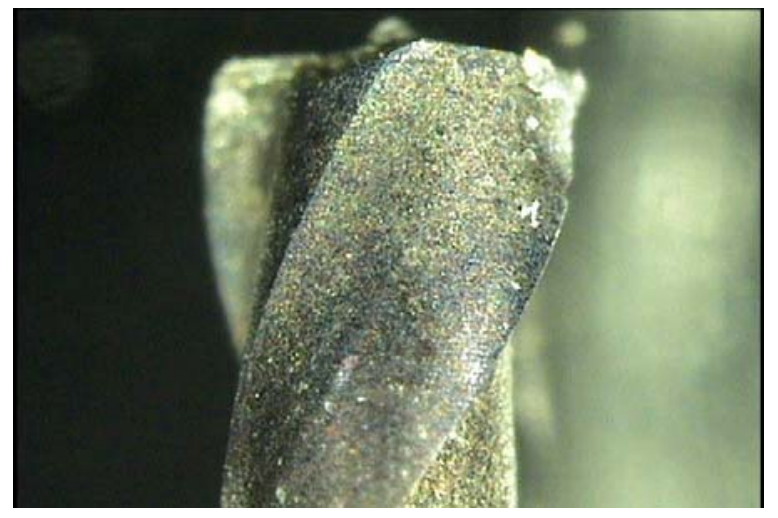

Fig.3. The magnified image of micro end milling tool after machining with optimum level of cutting parameters

Table: 5. The calculated BC two-way table for MRR

\begin{tabular}{|c|l|l|l|l|}
\hline Factor & \multicolumn{1}{|c|}{$\mathbf{B}_{\mathbf{0}}$} & \multicolumn{1}{|c|}{$\mathbf{B}_{\mathbf{1}}$} & \multicolumn{1}{c|}{$\mathbf{B}_{\mathbf{2}}$} & \multicolumn{1}{c|}{ Total } \\
\hline $\mathbf{C}_{\mathbf{0}}$ & $-2.444-1.315-1.075=-4.834$ & $-1.772-1.075-1.07=-3.922$ & $-1.442-0.99-0.912=-3.344$ & -12.10 \\
\hline $\mathbf{C}_{\mathbf{1}}$ & $-2.092-1.075-1.075=-4.242$ & $-1.442-0.568-0.694=-2.704$ & $-0.99+0.114-0.754=-1.63$ & -8.576 \\
\hline $\mathbf{C}_{\mathbf{2}}$ & $-1.442-0.796-0.99=-3.228$ & $-1.315+0.136-0.694=-1.873$ & $-0.568+0.248-0.638=-0.958$ & -6.059 \\
\hline Total & -12.304 & -8.499 & -5.932 & -26.735 \\
\hline
\end{tabular}




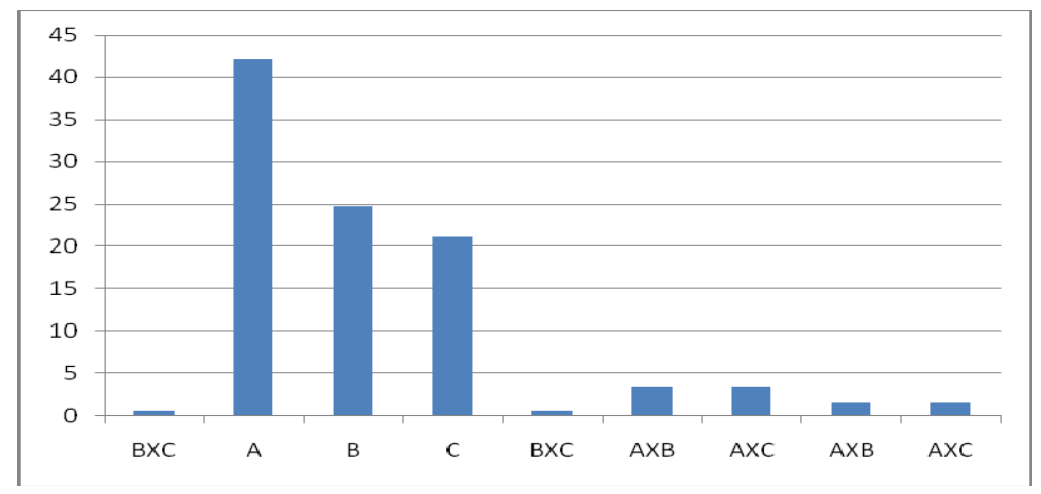

Fig4.Pareto diagram
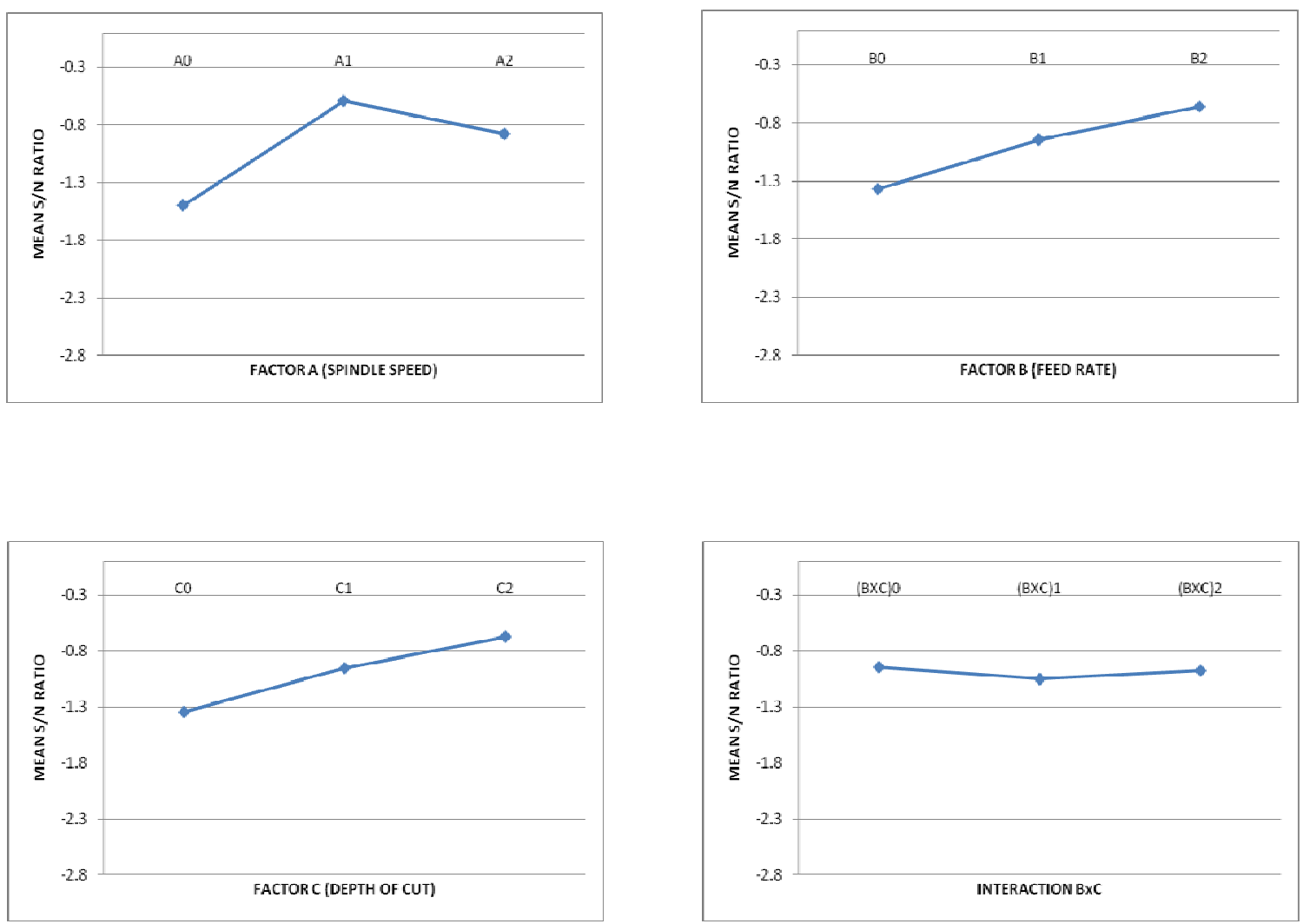

Fig5. The smaller the better S/N graph for MRR 
Table: 6. Pareto ANOVA analysis for MRR

\begin{tabular}{|c|c|c|c|c|c|c|c|c|c|}
\hline \multicolumn{10}{|c|}{ Factor and interaction } \\
\hline & B X C & $\mathbf{A}$ & $\overline{\mathbf{B}}$ & C & B X C & A X B & A X C & A X B & A X C \\
\hline $\begin{array}{c}\text { Sum at } \\
\text { factor level }\end{array}$ & \multirow[t]{2}{*}{-8.496} & \multirow[t]{2}{*}{-13.507} & \multirow[t]{2}{*}{-12.304} & \multirow[t]{2}{*}{-12.10} & \multirow[t]{2}{*}{-8.337} & \multirow[t]{2}{*}{-9.069} & \multirow[t]{2}{*}{-8.593} & \multirow[t]{2}{*}{-9.789} & \multirow[t]{2}{*}{-9.509} \\
\hline 0 & & & & & & & & & \\
\hline 1 & -9.459 & -5.321 & -8.499 & -8.576 & -9.276 & -10.019 & -10.226 & -8.297 & -7.998 \\
\hline 2 & -8.78 & -7.907 & -5.932 & -6.059 & -9.122 & -7.647 & -7.916 & -8.649 & -9.228 \\
\hline $\begin{array}{lr}\text { Sum of } \\
\text { squares of } \\
\text { difference (S) }\end{array}$ & 1.4691 & 105.058 & 61.6699 & 55.2476 & 1.5217 & 8.551 & 8.4611 & 3.65 & 3.875 \\
\hline $\begin{array}{l}\text { Contribution } \\
\text { ratio }(\%)\end{array}$ & $0.59 \%$ & $42.11 \%$ & $24.72 \%$ & $22.14 \%$ & $0.61 \%$ & $3.43 \%$ & $3.39 \%$ & $1.46 \%$ & $1.55 \%$ \\
\hline
\end{tabular}

Check on Significant interaction: BC two way table (Table: 5)

Optimum combination of significant factor level: $\mathrm{A}_{1} \mathrm{~B}_{2} \mathrm{C}_{2}$

Table: 7. Confirmation Experiment

\begin{tabular}{|c|c|c|c|c|c|}
\hline $\begin{array}{l}\text { Optimized } \\
\text { parameter for } \\
\text { the micro-end } \\
\text { milling process }\end{array}$ & $\begin{array}{c}\text { Using } \\
\text { Taguchi } \\
\text { technique }\end{array}$ & $\begin{array}{l}\text { Using Pareto } \\
\text { ANOVA }\end{array}$ & $\begin{array}{c}\text { Measured } \\
\text { value of } \\
\text { Response }\end{array}$ & $\begin{array}{c}\text { Predicted } \\
\text { value of } \\
\text { Response }\end{array}$ & $\begin{array}{l}\text { Percentage } \\
\text { Error }\end{array}$ \\
\hline $\begin{array}{l}\text { 1.Spindle speed in } \\
\text { rpm (Factor A) }\end{array}$ & $\begin{array}{c}\mathrm{A}_{1}= \\
\text { 70000rpm }\end{array}$ & $\mathrm{A}_{1}=70000 \mathrm{rpm}$ & \multirow{3}{*}{$\begin{array}{c}\mathrm{MRR}= \\
1.38 \mathrm{~mm}^{3} / \mathrm{min}\end{array}$} & \multirow{3}{*}{$\begin{array}{c}\mathrm{MRR}= \\
1.33 \mathrm{~mm}^{3} / \mathrm{min}\end{array}$} & \multirow{3}{*}{$3.62 \%$} \\
\hline $\begin{array}{c}\text { 2.Feed rate in } \\
\mu \mathrm{m} / \mathrm{sec} \text { (Factor } B \text { ) }\end{array}$ & $\begin{array}{l}B_{2}=0.8 \\
\mu \mathrm{m} / \mathrm{sec}\end{array}$ & $\begin{array}{l}B_{2}=0.8 \\
\mu \mathrm{m} / \mathrm{sec}\end{array}$ & & & \\
\hline $\begin{array}{l}\text { 3.Depth of cut in } \\
\mu \mathrm{m} \text { (Factor C) }\end{array}$ & $\mathrm{C}_{2}=40 \mu \mathrm{m}$ & $\mathrm{C}_{2}=40 \mu \mathrm{m}$ & & & \\
\hline
\end{tabular}

\section{Conclusions}

Based on this experimental work and analysis for the micro-end milling process using Taguchi technique and Pareto ANOVA, it is concluded that the Taguchi's robust design of experiment technique is suitable to analyze the micro-end milling problems. From this experimental work shows the optimal parameters for micro-end milling process using Taguchi approach and Pareto ANOVA for data analysis draw same conclusion. In this experimental work it is concluded that use of medium value of spindle speed, higher value of depth of cut and higher value of feed rate are recommended to obtain the maximum MRR in micro-end milling process. The optimum micro-end milling process parameters for maximum MRR are determines as spindle speed $=70000 \mathrm{rpm}$, feed rate $=0.8 \mu \mathrm{m} / \mathrm{sec}$ and depth of cut $=40 \mu \mathrm{m}$. The optimized machining parameters were used for the confirmation of experiments for validation; the measured value for the MRR is $1.38 \mathrm{~mm}^{3} / \mathrm{min}$.

\section{Nomenclature}

$s_{y}^{2} \quad$ The variance of $y$

y The measured data,

$\bar{y} \quad$ The average of measured data,

$\mathrm{n} \quad$ The number of samples 


\section{References}

Asad A.B.M.A., Takeshi Masaki, Rahman M., Lim H.S., Wong Y.S., 2007. Tool-based micro-machining, J. Mater. Process. Technol., Vol. 192-193, pp. 204-211

Azizur Rahman M, Rahman M, Senthil Kumar A, Lim H.S, 2005. CNC micro-turning: an application to miniaturization, Int. J. Machine Tools Manuf. Vol. 45, pp. 631-639.

Bao W.Y., Tansel I.N., 2000. Modeling micro-end-milling operations. Part I: Analytical cutting force model, Int. J. Machine Tools Manuf. Vol. 40, pp. 2155-2173.

Bao W.Y., Tansel I.N., 2000. Modeling micro-end-milling operations. Part II: Tool runout, Int. J. Machine Tools Manuf., Vol. 40 pp. 2175-2192.

Bao W.Y., Tansel , I.N. 2000. Modeling micro-end-milling operations. Part III: influence of tool wear, Int. J. Machine Tools Manuf. Vol. 40, pp. 2193-2211.

Bigot S., Valentincic J., Blatnik O., Junkar M., 2006. Micro-EDM parameters optimization, Second International Conference on Multi-material Micro Manufacture, Grenoble, France, September 20-22.

Bissacco G.. Valentincic J...Hansen H.N. Wiwe B.D., 2010. Towards the effective tool wear control in micro-EDM milling, Int $J$ Adv. Manuf. Technol., Vol. 47, pp. 3-9.

Fujimasa I., 1996. Micromachines: A new era in mechanical engineering, Oxford University Press.

Ghani J.A, Choudhury I.A, Hassan H.H., 2004. Application of Taguchi method in the optimization of end milling parameters, Journal of Materials Processing Technology, Vol. 145, pp. 84-92.

Lee.K., Dornfeld.D.A., 2004. A study of surface roughness in the micro end milling process, Consortium on deburring and edge finishing, Laboratory for manufacturing and sustainability, UC Berkeley.

Li C., Lai X., Li H. and Ni J. 2007. Modeling of three dimensional cutting forces in micro-end milling, J. Micromech.Microeng, Vol. 17, pp. 671-678.

Lu Z., Yoneyama T., 1999. Micro cutting in the micro lathe turning system, Int. J. Machine Tools Manuf. Vol. 39, pp. 1171-1183.

Malekian M., Park S.S., Jun M.B.G. 2009. Tool wear monitoring of micro-milling operations, Journal of Materials Processing Technology, pp. 4903-4914.

Park S.H., 1996. Robust Design and Analysis for Quality Engineering, Chapman \& Hall, London.

Phadke M.S., 1989. Quality Engineering Using Robust Design, Prentice-Hall, Englewood Cliffs, NJ.

Popov K., Dimov S., Ivanov A., Pham D.T, Gandarias E., 2010. New tool-workpiece setting up technology for micro-milling, Int $J$ Adv Manuf Technol, Vol. 47, pp. 21-27.

Prakash J.R.S., Senthil kumar A., Rahman M., Lim S.C., 2001. A model for predicting tool life for coated micro end mill, Proc. Fourth International Machining and Grinding, Troy, Michigan 7-10 May, pp. 149-158.

Rahman M, Lim H.S, Neo K.S, Senthilkumar A, Wong Y.S, Li X.P 2007. Tool based nano finishing and micromachining, Journal of Materials Processing Technology, Vol. 185, pp. 2-16.

Rahman M., Kumar S., Prakash J.R.S., 2001. Micro milling of pure copper, J. Mater. Process. Technol., Vol. 116, pp. 39-43.

Singh H., Kumar P., 2004. Tool wear optimization in turning operation by Taguchi method', Indian Journal of Engineering and Material Sciences. Vol.11, pp:19-24.

Son S.M., Lim H.S., Ahn J.H., 2005. Effects of the friction co-efficient on the minimum cutting thickness in micro cutting, Int. J. Machine Tools Manuf., Vol. 45, pp. 529-535.

Unal R, Dean E.B., 1991. Taguchi approach to design optimization for quality and cost: an overview, in: Proceedings of the International Society of Parametric Analyst 13th Annual, May 21-24.

Wang W., Kweon S.H., Yang. S.H., 2005. A study on roughness of the micro end milled surface produced by a miniature machine tool, J. Mater. Process. Technol., Vol. 162-163, pp. 702-708.

Yang K., Liang Y.C., Zhen K.N., Bai Q.S., Chen W.Q. 2011. Tool edge radius effect on cutting temperature in micro end milling process Int J Adv Manuf Technol, 52:905-912,DOI 10.1007/s00170-010-2795-z

Yu Z.Y., Masuzawa T. Fujino M., 1998. Micro-EDM for three dimensional cavities-Development of uniform wear method, Annals of the CIRP. Vol. 47, No. 1.

\section{Biographical notes}

Mr. PR. Periyanan is an Asst. Professor in Mechanical Engineering Department, Sudharsan Engineering College, India. He obtained M.E in Manufacturing Engineering from Anna University Chennai, India. He has more than 10 years of experience in Teaching and Industrial field. He has published many papers in National and International journals.

Dr. U. Natarajan is an Asst. Professor in Mechanical Engineering Department, A.C.College of Engineering and Technology, India. He got his ME in Manufacturing Engineering from NIT Tiruchirappalli, India, Ph.D.from AnnaUniversity Chennai, India and PDF from Kyungpook National University, Daegu, South Korea, He has more than 20 years of experience in Teaching and Industrial field He has published more than 50 papers in National and International journals. 
Dr. S.H. Yang is a Professor in School of Mechanical engineering, Kyungpook National University, Daegu, South Korea. He got his MS from University of Illinois, USA, PhD from University of Michigan at AnnArbor, USA. He has published many research papers in National and International journals.

Received May 2011

Accepted November 2011

Final acceptance in revised form December 2011 